\title{
Материалы на основе твердых растворов теллуридов висмута и сурьмы, полученные методами быстрой кристаллизации расплава
}

\author{
(С) Л.Д. Иванова, Ю.В. Гранаткина, А.Г. Мальчев, И.Ю. Нихезина, М.В. Емельянов \\ Институт металлургии и материаловедения им. А.А. Байкова Российской академии наук, \\ 119334 Москва, Россия \\ E-mail: ivanova@imet.ac.ru
}

(Поступила в Редакцию 20 декабря 2018 г.

В окончательной редакции 24 декабря 2018 г.

Принята к публикации 28 декабря 2018 г.)

Исследованы твердые растворы $\mathrm{Bi}_{0.5} \mathrm{Sb}_{1.5} \mathrm{Te}_{3}$ р-типа проводимости, полученные горячим прессованием и экструзией порошков, приготовленных методами быстрой кристаллизации расплава: спиннингованием расплава и кристаллизацией расплава в жидкости. Морфология порошков, поверхности скола образцов и их микроструктура изучены с помощью оптической, сканирующей электронной и туннельной микроскопии. Механические свойства образцов исследованы при деформации сжатием при комнатной температуре. Коэффициент Зеебека, электропроводность и теплопроводность материалов измерены в интервале температур $100-600 \mathrm{~K}$. Для материалов, экструдированных из гранул, полученных кристаллизацией расплава в воде и измельченных в планетарной мельнице, получена наибольшая величина предела прочности на сжатие $\sigma_{B}=145 \mathrm{MПа} \mathrm{при} 300 \mathrm{~K}$ и максимальная термоэлектрическая добротность $(Z T)_{\max }=1.34$ при $370 \mathrm{~K}$.

DOI: $10.21883 /$ FTP.2019.05.47558.16

\section{1. Введение}

В настоящее время установлено, что использование мелкозеренных и нанокристаллических структур позволяет получить повышение эффективности термоэлектрических материалов. Перспективными методами синтеза таких материалов являются спиннингование, искровое плазменное спекание и экструзия [1]. Материалы на основе твердых растворов $\mathrm{Sb}_{2} \mathrm{Te}_{3}-\mathrm{Bi}_{2} \mathrm{Te}_{3}$ используются для изготовления $p$-ветвей термоэлектрических устройств, работающих в диапазоне температур 200-500 K. В данной работе рассмотрены два метода получения гранул твердого раствора $\mathrm{Bi}_{0.5} \mathrm{Sb}_{1.5} \mathrm{Te}_{3}$ : спиннингование расплава и охлаждение расплава в жидкости. Скорость охлаждения расплава может достигать $10^{5} \mathrm{~K} / \mathrm{c}$, и при такой скорости охлаждения возможен переход жидкой фазы в твердую фазу того же состава. Целью данной работы является сравнение механических и термоэлектрических свойств образцов, приготовленных горячим прессованием и экструзией порошков, полученных указанными выше методами.

\section{2. Результаты и обсуждения}

Одним из способов получения мелких частиц, из которых потом формируются компактные материалы, является быстрая закалка расплава на охлаждаемом вращающемся диске (спиннингование расплава). Морфология таких частиц исследована с помощью сканирующей растровой электронной микроскопии (РЭМ) (рис. $1, a, b, c)$. В этом случае частицы имеют форму пластин, состоящих из тонких чешуек, расположенных своей плоской стороной перпендикулярно охлаждаемой поверхности диска. Чешуйки имеют толщину порядка сотен нм и длину несколько мкм. Другой способ получения гранул твердого раствора $\mathrm{Bi}_{0.5} \mathrm{Sb}_{1.5} \mathrm{Te}_{3}-$ быстрая кристаллизация расплава в охлаждаемой жидкости. В зависимости от температуры кристаллизации такие гранулы имеют различную форму и размеры. На рис. 1 приведены РЭМ-изображения гранул, полученных спиннингованием расплава (рис. $1, a-c$ ) и кристаллизацией расплава погружением в жидкий азот (рис. $1, d$ ), в этанол, охлажденный жидким азотом (рис. 1,e), и в воду (рис. $1, f$ ); температуры кристаллизации 100, 180 и $300 \mathrm{~K}$ соответственно.

Образцы, полученные горячим прессованием частиц, приготовленных спиннингованием расплава, имеют слоистую мелкокристаллическую структуру с зернами менее десятков мкм, так как во время горячего прессования частицы рассыпаются на мелкие чешуйки, из которых и формируются образцы. Микроструктура поверхностей скола таких образцов была нами исследована с помощью РЭМ в [2].

Гранулы, полученные кристаллизацией расплава в жидкости, измельчали в ступке, ножевой и планетарной мельницах и использовали для приготовления образцов горячим прессованием и экструзией. РЭМ-изображения и полученные в оптическом микроскопе микрофотографии поверхностей скола образцов были приведены в [3]. Горячепрессованные и экструдированные образцы, полученные из гранул, измельченных в ножевой мельнице, имели хорошо выраженную слоистую микроструктуру с вытянутыми зернами длиной до сотен мкм, толщиной от нескольких десятых до нескольких единиц мкм. Образцы, полученные из гранул, измельченных в планетарной 

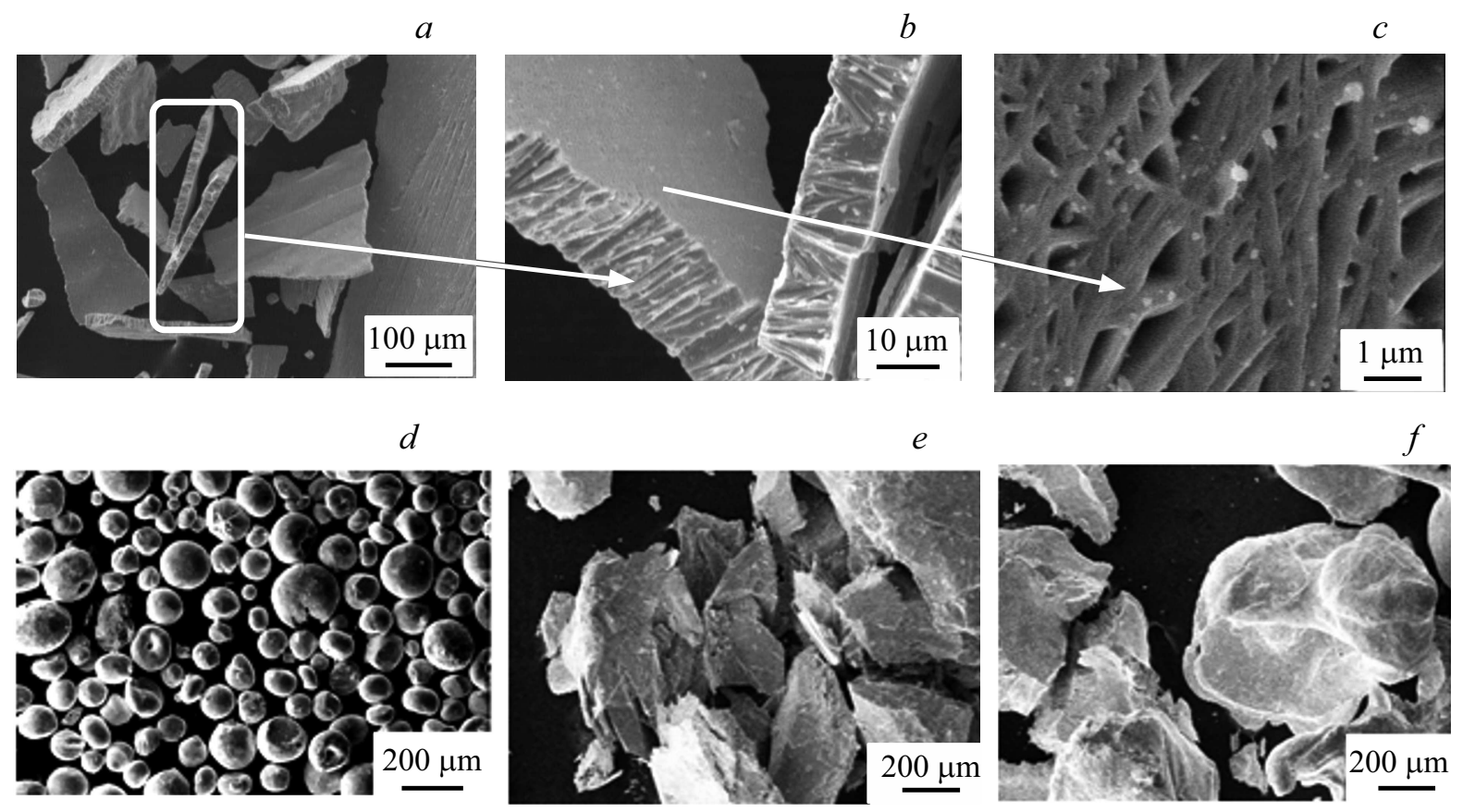

Рис. 1. РЭМ-изображения частиц, полученных спиннингованием расплава $(a, b, c)$ и гранул, приготовленных кристаллизацией расплава погружением в жидкий азот $(d)$, в спирт, охлажденный жидким азотом, $(e)$ и в воду $(f)$.

мельнице, имели мелкозеренную структуру, размеры зерен в образцах не превышали нескольких мкм. Все образцы содержали небольшое количество второй фазы (эвтектики на основе теллура), которая проявляется на снимках поверхностей скола образцов, полученных в оптическом микроскопе (рис. 2,a) и сканирующем туннельном микроскопе (рис. 2, $b, c$ ). Вторая фаза светлее (белые включения), чем основное поле.

Механические свойства (предел прочности, и модуль упругости) образцов исследованы в условиях деформации сжатием при комнатной температуре. Данные представлены в табл. 1. Образцы получены горячим прессованием и экструзией частиц, приготовленных кристаллизацией расплава в жидкости при температуре $T_{\mathrm{cr}}(1-6)$ и спиннингованием расплава (образец 7). Температуры кристаллизации: $300 \mathrm{~K}$ (образцы 1-5) и $180 \mathrm{~K}$ (образец 6). Гранулы измельчали в ступке (образцы 1,2), в ножевой мельнице (образец 3 ) и в планетарной мельнице (образцы 4-6). Установлено, что разрушение всех образцов хрупкое. Наименьший предел прочности $\sigma_{B}$ имели горячепрессованные образцы из гранул, измельченных в ножевой мельнице $\left(\sigma_{B}=64 \mathrm{MПа}\right)$ и из частиц, полученных спиннингованием расплава $\left(\sigma_{B}=62 \mathrm{MПа}\right)$. Наиболее высокий предел прочности получили для образца, экструдированного из гранул, измельченных в планетарной мельнице (образец 4, $\sigma_{B}=145 \mathrm{MПа).}$

Термоэлектрические параметры (коэффициент Зеебека, электропроводность, теплопроводность, коэффи-

Таблица 1. Прочностные характеристики при $300 \mathrm{~K}$ : предел прочности $\sigma_{B}$, деформация $\varepsilon_{B}$ и коэффициент упругости $d \sigma / d \varepsilon$ горячепрессованных и экструдированных образцов из гранул, полученных кристаллизацией расплава в жидкости (1-6) и спиннингованием расплава (7)

\begin{tabular}{|c|c|c|c|c|c|c|}
\hline $\begin{array}{l}\text { Номер } \\
\text { образца }\end{array}$ & $\begin{array}{c}\text { Приготовление } \\
\text { гранул }\end{array}$ & $\begin{array}{c}\text { Получение } \\
\text { порошка }\end{array}$ & $\begin{array}{l}\text { Получение } \\
\text { образцов }\end{array}$ & $\begin{array}{r}\sigma_{B}, \\
\text { МПа }\end{array}$ & $\begin{array}{c}\varepsilon_{B}, \\
\%\end{array}$ & $\begin{array}{c}d \sigma / d \varepsilon, \\
\Gamma П а\end{array}$ \\
\hline 1 & $T_{\text {cr }}=300 \mathrm{~K}$ & $\mathrm{C}$ & $Э$ & 110 & 0.7 & 16 \\
\hline 2 & $T_{\mathrm{cr}}=300 \mathrm{~K}$ & $\mathrm{C}$ & ГП & 85 & 0.8 & 11 \\
\hline 3 & $T_{\mathrm{cr}}=300 \mathrm{~K}$ & HM & ГП & 66 & 1.0 & 7 \\
\hline 4 & $T_{\mathrm{cr}}=300 \mathrm{~K}$ & ПМ & $\ni$ & 145 & 0.8 & 18 \\
\hline 5 & $T_{\mathrm{cr}}=300 \mathrm{~K}$ & ПМ & ГП & 110 & 0.7 & 16 \\
\hline 6 & $T_{\mathrm{cr}}=180 \mathrm{~K}$ & ПМ & ГП & 120 & 0.8 & 15 \\
\hline 7 & спин. & - & ГП & 62 & 2.5 & 2.5 \\
\hline
\end{tabular}

Примечание. С - ступка, НМ - ножевая мельница, ПМ - планетарная мельница, ГП - горячее прессование, Э - экструзия, $T_{\mathrm{cr}}-$ температура кристаллизации; спин. - спиннингование. 

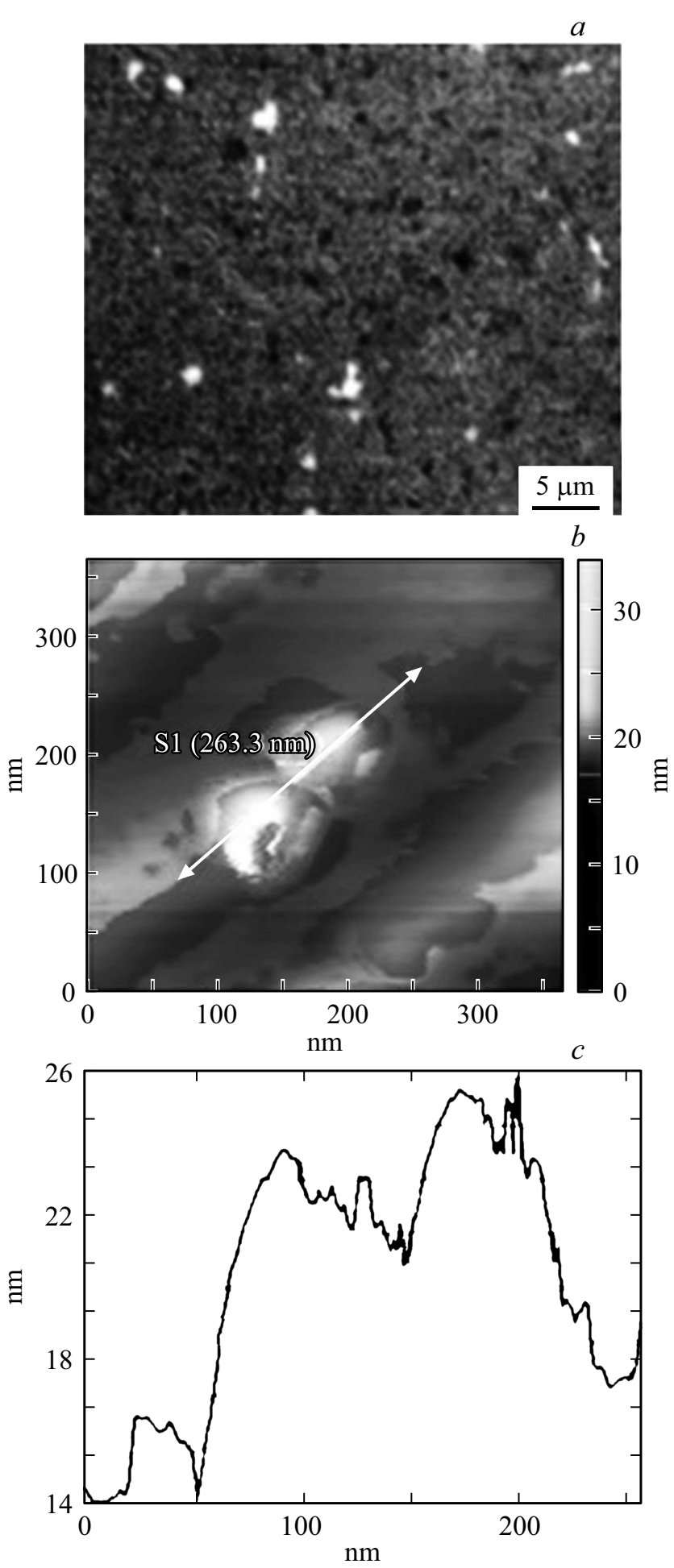

Рис. 2. Микрофотография, полученная в оптическом микроскопе $(a)$, СТМ-изображение $(b)$ и профиль поверхности $(c)$ образца.

циент термоэлектрической добротности) измерены при комнатной температуре $(300 \mathrm{~K})$ и в интервале температур $100-600 \mathrm{~K}$. Полученные данные и вычисленные значения решеточной составляющей теплопроводности $\kappa_{l}$ и термоэлектрической добротности $Z T$ при
$300 \mathrm{~K}$ приведены в табл. 2. Образцы имели коэффициент Зеебека от 203 до $238 \mathrm{м \kappa B} / \mathrm{K}$, электропроводность от 925 до $577 \mathrm{CM} / \mathrm{cm}$, теплопроводность от $12.6 \cdot 10^{-3}$ до $9 \cdot 10^{-3} \mathrm{BT} / \mathrm{cm} \cdot \mathrm{K}$. Для всех исследованных образцов значения $Z T$ при $300 \mathrm{~K}$ составили $(1.05 \pm 0.15)$. На рис. 3 приведены температурные зависимости термоэлектрических характеристик горячепрессованных и экструдированных образцов из порошков, полученных кристаллизацией расплава в жидкости и спиннингованием расплава, термоэлектрические свойства которых при $300 \mathrm{~K}$ приведены в табл. 2. Температурные зависимости коэффициента Зеебека $\alpha(T)$ имеют вид кривых с максимумом при температурах $340-370 \mathrm{~K}$.
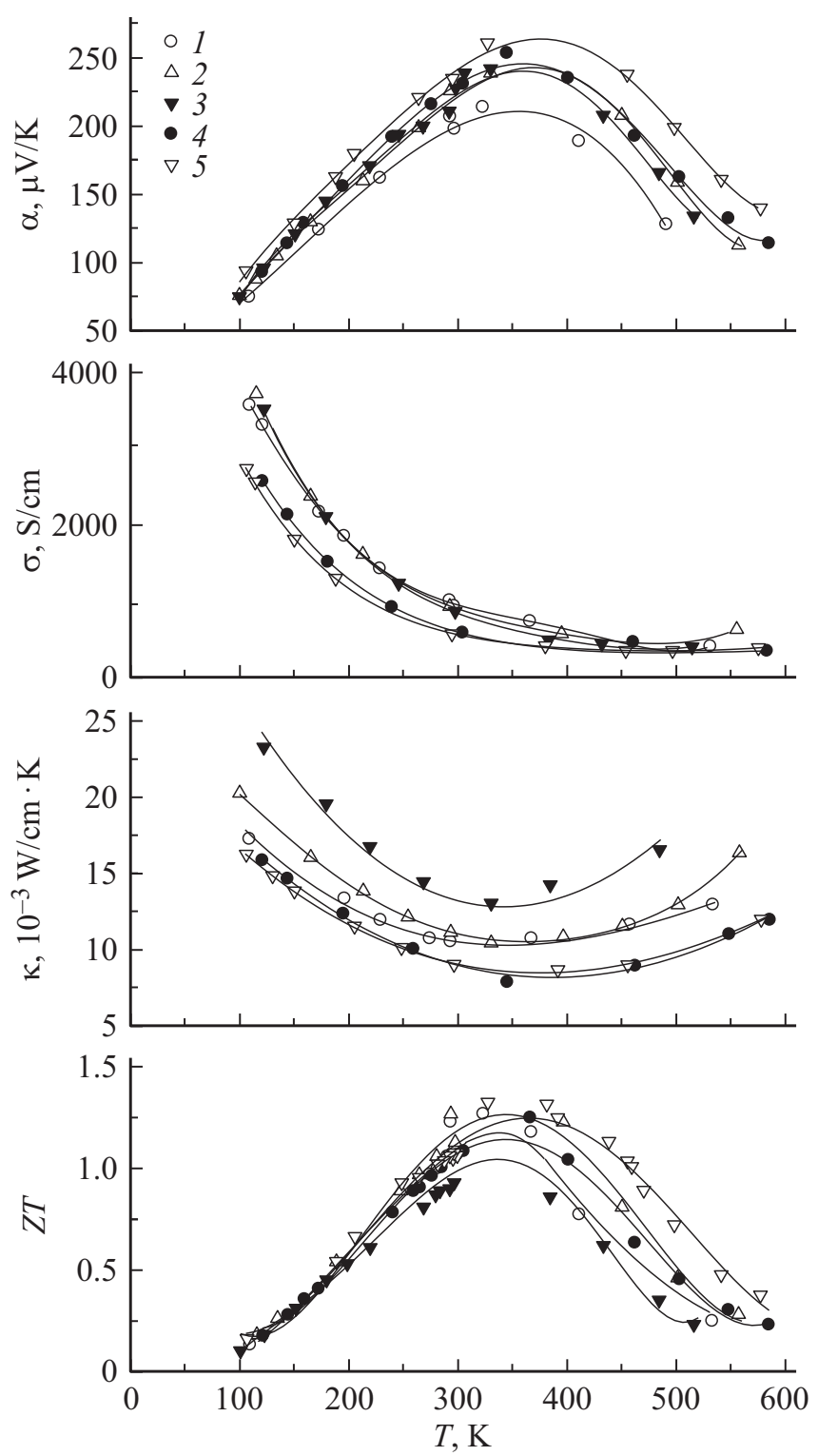

Рис. 3. Температурные зависимости коэффициента Зеебека $\alpha$, электропроводности $\sigma$, коэффициента теплопроводности $\kappa$ и термоэлектрической эффективности $Z T$ образцов, полученных кристаллизацией расплава в жидкости и спиннингованием расплава. Номера кривых соответствуют номерам образцов в табл. 2 и 3. 
Таблица 2. Термоэлектрические свойства образцов: коэффициент Зеебека $\alpha$, электропроводность $\sigma$, коэффициент теплопроводности $\kappa$ и термоэлектрическая добротность $Z T$ образцов, полученных горячим прессованием и экструзией из гранул, измельченных в планетарной мельнице, приготовленных кристаллизацией расплава в жидкости $(1-3)$ и спиннингованием расплава $(4,5)$

\begin{tabular}{|c|c|c|c|c|c|c|c|}
\hline $\begin{array}{l}\text { Номер } \\
\text { образца }\end{array}$ & $\begin{array}{c}\text { Приготовление } \\
\text { гранул }\end{array}$ & $\begin{array}{c}\text { Получение } \\
\text { образцов }\end{array}$ & $\begin{array}{c}\alpha, \\
\text { мкВ/K }\end{array}$ & $\begin{array}{c}\sigma, \\
\mathrm{CM} / \mathrm{cm}\end{array}$ & $\begin{array}{c}\kappa \cdot 10^{3}, \\
\mathrm{BT} / \mathrm{cm} \cdot \mathrm{K}\end{array}$ & $\begin{array}{c}\kappa_{l} \cdot 10^{3}, \\
\mathrm{BT} / \mathrm{cm} \cdot \mathrm{K}\end{array}$ & $Z T$ \\
\hline 1 & $T_{\mathrm{cr}}=300 \mathrm{~K}$ & ГП & 203 & 925 & 10.1 & 5.7 & 1.1 \\
\hline 2 & $T_{\mathrm{cr}}=300 \mathrm{~K}$ & $Э$ & 221 & 862 & 10.8 & 6.5 & 1.2 \\
\hline 3 & $T_{\mathrm{cr}}=180 \mathrm{~K}$ & $\ni$ & 223 & 785 & 12.6 & 8.5 & 0.9 \\
\hline 4 & спин. & ГП & 230 & 617 & 9.1 & 6.2 & 1.1 \\
\hline 5 & спин. & ГП & 238 & 577 & 9.0 & 6.3 & 1.1 \\
\hline
\end{tabular}

Примечание. ГП - горячее прессование, Э - экструзия; $T_{\mathrm{cr}}$ - температура кристаллизации, спин. - спиннингование.

Таблица 3. Параметры температурных зависимостей коэффициента Зеебека $A(\alpha=A \ln T)$, электропроводности $r\left(\sigma \propto T^{r}\right)$, максимальные значения коэффициента Зеебека $\left(\alpha_{\max }\right)$ и максимальные значения термоэлектрической эффективности $(Z T)_{\max }$ при температуре $T_{\max }$ для образцов, полученных различными методами (см. табл. 2)

\begin{tabular}{c|c|c|c|c|c}
\hline $\begin{array}{c}\text { Номер } \\
\text { образцов }\end{array}$ & $T_{\max }, \mathrm{K}$ & $\alpha_{\max }$, мкB/K & $(Z T)_{\max }$ & $r$ & $A$, мкB/K \\
\hline 1 & 345 & 215 & 1.23 & -1.5 & 133 \\
2 & 370 & 235 & 1.34 & -1.6 & 142 \\
3 & 350 & 235 & 1.07 & -1.8 & 140 \\
4 & 340 & 245 & 1.14 & -1.58 & 145 \\
\end{tabular}

Электропроводность образцов $1,3,4,5$ в температурном интервале $100-600 \mathrm{~K}$ уменьшается с ростом температуры, электропроводность образца 2 с ростом температуры уменьшается в интервале $100-500 \mathrm{~K}$ и начинает возрастать при температурах $>500 \mathrm{~K}$. Такой характер зависимостей является типичным для вырожденных полупроводников. Теплопроводность образцов начинает возрастать при температурах $>350 \mathrm{~K}$. Рассчитанные значения $Z T$ в интервале температур $100-600 \mathrm{~K}$ также представлены на рис. 3. Эти зависимости имеют форму кривых с максимумом при $340-370 \mathrm{~K}$. В табл. 3 приведены параметры температурных зависимостей коэффициента Зеебека $\alpha=f(\ln T), A$, электропроводности $\lg \sigma=f(\lg T), r$, рассчитанные по наклону кривых в области температур от температуры Дебая $(155 \mathrm{~K})$ до $300 \mathrm{~K}$, максимум коэффициента Зеебека $\left(\alpha_{\max }\right)$ и максимум термоэлектрической добротности $(Z T)_{\max }$ при температуре $T_{\max }$ для образцов, полученных различными методами, указанными в табл. 2. Для исследованных материалов эти параметры составили $A=(146 \pm 14)$ мкВ/K, $r=-(1.65 \pm 0.015)$. Полученные значения близки к теоретическим: $A=129 \mathrm{мкB} / \mathrm{K}, r=-1.5$ для параболической зонной структуры и акустического механизма рассеяния носителей заряда [4]. Расчеты показали, что $(Z T)_{\max }=(1.3 \pm 0.05)$ для экструдированного (2) и горячепрессованного (1) образцов из гранул, полученных кристаллизацией расплава в воде при $300 \mathrm{~K}$, и для горячепрессованного образца (5) из частиц, полученных спиннингованием расплава.

\section{3. Заключение}

Рассмотрены два метода получения порошков твердого раствора $\mathrm{Bi}_{0.5} \mathrm{Sb}_{1.5} \mathrm{Te}_{3}$ быстрой кристаллизацией расплава: спиннингование расплава и кристаллизация расплава в жидкости. Образцы получали горячим прессованием и экструзией порошков. Исследованы макрои микроструктура порошков и образцов, механические и термоэлектрические свойства образцов в зависимости от метода их приготовления.

Преимущества этих методов:

- можно не проводить предварительное расплавление исходных компонентов в кварцевых ампулах;

- состав получаемых частиц твердого раствора близок к стехиометрическому и соответствует составу исходной загрузки;

- не надо измельчать для прессования частицы, полученные спиннингованием расплава.

Максимальный предел прочности $\sigma_{B}=145$ МПа при деформировании сжатием при $300 \mathrm{~K}$ получен для материалов, экструдированных из гранул, приготовленных кристаллизацией расплава в воде и измельченных в планетарной мельнице.

Максимальная термоэлектрическая добротность $(Z T)_{\max } \approx 1.2$ при $350 \mathrm{~K}$ получена для горячепрессованных материалов из порошка, приготовленного спиннингованием расплава, и из горячепрессованных и экструдированных материалов из гранул, полученных кристаллизацией расплава в воде при $300 \mathrm{~K}$ и измель- 
ченных в планетарной мельнице. Наибольшую величину $(Z T)_{\max }=1.34$ при $370 \mathrm{~K}$ имеют материалы, экструдированные из гранул, полученных кристаллизацией расплава в воде, и измельченные в планетарной мельнице.

Работа выполнена по государственному заданию № 007-00129-18-00 и при финансовой поддержке РФФИ, проект № 16-08-00033a.

\section{Список литературы}

[1] Л.Д. Иванова. ФТП, 51 (7), 948 (2017).

[2] Л.Д. Иванова, Л.И. Петрова, Ю.В. Гранаткина, В.Г. Леонтьев, А.С. Иванов, С.А. Варламов, Ю.П. Прилепо, А.М. Сычёв, А.Г. Чуйко, И.В. Башков. Неорг. матер., 49 (2), 110 (2013).

[3] Д.С. Никулин, Л.Д. Иванова, Ю.В. Гранаткина, Л.И. Петрова, И.Ю. Нихезина, А.Г. Мальчев. ФТП, 51 (7), 955 (2017).

[4] Б.М. Гольцман, В.А. Кудинов, И.А. Смирнов. Полупроводниковые термоэлектрические материалы на основе $\mathrm{Bi}_{2} \mathrm{Te}_{3}$ (М., Наука, 1972).

Редактор Л.В. Шаронова

\section{Materials on the basis of bismuth and antimony tellurides prepared by rapid melt solidification methods}

\section{L.D. Ivanova, Yu.V. Granatkina, A.G. Malchev, I.Yu. Nikhezina, M.V. Emel'anov}

Baikov Institute of Metallurgy and Materials Science, Russian Academy of Sciences, 119334 Moscow, Russia

Abstract The materials of $p$-type conductivity $\mathrm{Bi}_{0.5} \mathrm{Sb}_{1.5} \mathrm{Te}_{3}$ solid solutions obtained by vacuum hot-pressing and extrusion powders prepared by rapid melt quenching methods - melt spinning and melt crystallization in liquid - are investigated. The morphology of powder and sample cleavage surface and their microstructure are analyzed by optical, scanning electron microscopy and scanning tunnel microscopy. The mechanical properties of the samples are investigated by compression tests at room temperatures. The Seebeck coefficient, electrical conductivity, and thermal conductivity of the materials were measured in the temperature range $100-600 \mathrm{~K}$. The samples extruded from granules obtained by melt crystallization in a water and crushed in ball mill have the highest strength $\sigma_{B}=145 \mathrm{MPa}$ at $300 \mathrm{~K}$ and the maximum thermoelectric efficiency amounts to $(Z T)_{\max }=1.34$ at $370 \mathrm{~K}$. 